\title{
SENTIDOS DE DIREITOS DE APRENDIZAGEM E CIDADANIA EM DOCUMENTOS CURRICULARES OFICIAIS: DISCURSO, ENSINO E SUBJETIVIDADE
}

\author{
MEANINGS OF LEARNING RIGHTS AND CITIZENSHIP IN OFFICIAL CURRICULUM \\ DOCUMENTS: DISCOURSE, TEACHING AND SUBJECTIVITY
}

\author{
Marisa Grigoletto ${ }^{1}$, Laura Fortes ${ }^{2}$ \\ ${ }^{1}$ Universidade de São Paulo (USP), São Paulo, SP, Brasil \\ mgrigol@usp.br \\ ${ }^{2}$ Universidade Federal da Integração Latino-Americana (UNILA), Foz do Iguaçu, PR, Brasil \\ laurafortes@yahoo.com
}

Recebido em 25 nov. 2019

Aceito em 16 dez. 2019

Resumo: Neste artigo, investigamos o discurso político-educacional produzido como parte de políticas públicas de ensino para a Educação Básica no Brasil na última década, com foco no recorte sobre ensino de língua inglesa. Constituímos um corpus de análise a partir de documentos de orientação curricular da Secretaria Municipal de Educação de São Paulo, produzidos entre 2015 e 2019, e estabelecemos relações intertextuais com outros documentos que fazem parte das políticas públicas de ensino (leis, diretrizes, orientações didáticas etc.). Nossa análise centrou-se em torno de formulações agrupadas em duas categorias: direitos de aprendizagem e sentidos de cidadania, com o objetivo de compreender o funcionamento de sentidos produzidos por/para uma política educacional de Estado para o ensino e algumas de suas implicações históricas, ideológicas e políticas constitutivas da relação língua/subjetividade. Destacaram-se sentidos voltados à aprendizagem como direito e à cidadania como objetivo final da formação escolar, o que nos permitiu concluir que se produz, como efeito, nesse discurso, um predomínio da forma-sujeito jurídica sobre outras subjetividades possíveis - e até mais prováveis nessa discursividade -, tais como a do sujeito educacional e a do sujeito social. Assim, cidadania e direitos de aprendizagem se constroem como promessa de plena adequação do sujeito social brasileiro, na posição de sujeito aprendiz, ao Estado Democrático de Direito e, no caso do ensino de Inglês, como promessa de obtenção, por parte do aprendiz, de uma "cidadania global".

Palavras-chave: Discurso político-educacional. Educação como direito. Educação para a cidadania.

\begin{abstract}
In this article, we investigate the political-educational discourse produced as part of public education policies for Basic Education in Brazil in the last decade, focusing specifically on English language education. The corpus studied was based on official curriculum guidelines of the Municipal Secretariat of Education of São Paulo, produced between 2015 and 2019, and intertextual relations were established with other documents that are part of the public policies of education (laws, guidelines, etc.). Our analysis focused on formulations grouped into two categories: learning rights and meanings of citizenship, with the aim of understanding the functioning of meanings produced by/for a State educational policy for teaching and some of its historical, ideological and political implications for the language/subjectivity relationship. Meanings focused on learning as a right and on citizenship as the final objective of school education were prevalent, which led us to the conclusion that this discourse produces, as an effect, a predominance of the legal subject-form over other possible subjectivities - and even more likely in this discursivity -, such as those of the educational subject and the social subject. Thus, citizenship and learning rights are built as a promise of full adaptation of the Brazilian social subject, in the subject position of learner, to the democratic State ruled by law and, in the case of the teaching of English, as a promise of obtaining, on the part of the learner, a "global citizenship".
\end{abstract}

Keywords: Political-educational discourse. Education as a right. Education for citizenship. 


\section{INTRODUÇÃO}

Pensar as questões de ensino numa perspectiva discursiva implica discutir suas possibilidades de sentido a partir das relações entre língua(gem), subjetividades e processos históricos - relações que se constroem nas/pelas políticas e práticas em jogo em diversos espaços sociais, e, em especial, na instituição escolar. As políticas e práticas educacionais inserem-se, assim, em determinadas discursividades, que constituem os sujeitos em seus processos de ensino e aprendizagem, ou seja, em suas relações com os saberes. Nesse sentido, falar em "educação como direito" e "educação para a cidadania", por exemplo, desloca-nos do campo das "obviedades" para uma compreensão desses enunciados como parte de um processo discursivo, em que entram em jogo memórias, redes de sentido, subjetividades.

Considerando que tais discursividades atravessam os documentos curriculares oficiais, investigamos o discurso político-educacional produzido como parte de políticas públicas de ensino para a Educação Básica no Brasil na última década, lançando um olhar analítico para esse discurso, no recorte sobre ensino de língua inglesa. $\mathrm{O}$ acontecimento que nos mobilizou para esta análise foi a implantação do ensino de Inglês no Ciclo I do Ensino Fundamental nas escolas da Rede Municipal de Ensino de São Paulo em 2012, cujos desdobramentos resultaram na publicação de documentos curriculares oficiais estabelecendo diretrizes metodológicas, teóricas, pedagógicas e didáticas específicas para esse contexto.

Desse modo, constituímos um corpus de análise a partir de documentos de orientação curricular da Secretaria Municipal de Educação de São Paulo, produzidos entre 2015 e 2019. Buscamos investigar relações intertextuais com outros documentos que fazem parte das políticas públicas de ensino (leis, diretrizes, orientações didáticas etc.), com o intuito de compreender relações interdiscursivas. Em uma primeira leitura do material, chamaram nossa atenção os sintagmas/significantes "direitos de aprendizagem", "cidadania" e "formação cidadã", que apareciam reiteradamente na textualidade dos documentos, produzindo um efeito de pré-construído (PÊCHEUX, [1975] 1988), um já-dito que funciona a partir de uma memória, sustentando seus sentidos. 
Procedemos a um recorte para a análise em torno de formulações que agrupamos em duas categorias: direitos de aprendizagem e sentidos de cidadania no discurso político-educacional. Nossos gestos de leitura, no decorrer da análise, buscaram, assim, compreender o funcionamento de sentidos produzidos por/para uma política educacional de Estado para o ensino, deixando entrever algumas de suas implicações históricas, ideológicas e políticas constitutivas da relação língua/subjetividade.

\section{DIREITOS DE APRENDIZAGEM: UM FUNCIONAMENTO DISCURSIVO}

Nesta seção, analisamos o funcionamento discursivo da expressão "direitos de aprendizagem", presente nos documentos educacionais da Secretaria Municipal de Educação de São Paulo, tomando-o como um enunciado e confrontando-o com outras expressões e enunciados da cena discursiva política e educacional no Brasil.

Duas razões justificam compreender "direitos de aprendizagem" como um enunciado, em seu funcionamento no discurso sob análise: a primeira é que pode ser desdobrado em várias afirmações, presentes nos textos dos documentos, como em "garantia dos Direitos de Aprendizagem, inalienáveis, de todas as crianças e jovens desta cidade", "os Direitos de Aprendizagem são relacionados à [...]" ou "os direitos de aprendizagem se consolidam pela [...]" (SÃO PAULO, 2016a, p. 7, 33 e 14, respectivamente); a segunda razão está no fato de que "direitos de aprendizagem" se apresenta como um postulado que leva a diretrizes a serem seguidas.

Comecemos mobilizando as noções de enunciado universal e enunciado histórico, em Orlandi (2012b), que aplicaremos ao nosso objeto de análise. Em seu texto (p. 154-155), a autora analisa dois enunciados e seus efeitos de sentido - 1 . Todos são iguais perante a lei; 2 . Todos têm direito à diferença - para sustentar que o primeiro "apresenta-se como universal face à configuração jurídica do cidadão", enquanto o segundo "apresenta-se como histórico" (grifos no original) porque significa diferentemente conforme as conjunturas históricas e porque depende do primeiro para se efetivar. Em outras palavras, o direito à diferença, qualquer que seja seu sentido, só encontra interpretação se o primeiro enunciado estiver significando. 
Trazendo essa distinção para nossa análise, há um enunciado inaugural da rede de expressões e enunciados - "direito à educação" -, presente na Constituição Federal de 1988, que se apresenta como universal, visto que nele "o jurídico funciona de forma pressuposta" (ORLANDI, 2012b, p. 155) ${ }^{1}$ :

Art. 205. A educação, direito de todos e dever do Estado e da família, será promovida e incentivada com a colaboração da sociedade, visando ao pleno desenvolvimento da pessoa, seu preparo para o exercício da cidadania e sua qualificação para o trabalho. (BRASIL, 1988) (grifos nossos)

Além de universal, esse enunciado produz uma relação a que Pêcheux dá o nome de efeito de sustentação (cf.: PÊCHEUX, [1975] 1988, p. 110) em virtude da construção por meio da incisa: "direito de todos e dever do Estado e da família", que corta a oração "A educação será promovida...". Ou seja, esse enunciado realiza uma articulação que evoca aquilo "que se sabe a partir de outro lugar" (PÊCHEUX, 1988 [1975], p. 111): “A educação é um direito de todos".

Podemos dizer que "direito à aprendizagem", enunciado presente no documento Diálogos interdisciplinares a caminho da autoria (SÃO PAULO, 2015, p. $7)^{2}$, assim como em publicação anterior do MEC (BRASIL, 2012, p. 18) ${ }^{3}$, funciona numa relação parafrástica e metonímica com "direito à educação", já que este último compreende o direito à aprendizagem.

Tomemos agora o enunciado "direitos de aprendizagem", ao qual os documentos da Secretaria Municipal de Educação de São Paulo dão bastante ênfase. ${ }^{4}$ Confrontando-o com "direito à educação", temos, de um lado, a repetição parafrástica direitos de aprendizagem - direito à aprendizagem; por outro lado, "direitos de aprendizagem" produz uma deriva, um deslizamento metafórico dos

\footnotetext{
${ }^{1}$ Tomamos como inspiração a análise de Orlandi exemplificativa do modo de funcionamento da linguagem pelos mecanismos da paráfrase e da metáfora, no texto citado.

2 "O presente documento busca [...] delinear uma trajetória com o conjunto de educadores e educadoras, no sentido de aproximar e aprimorar as práticas docentes, de modo a garantir o direito à aprendizagem".

3 "Ciclo de Alfabetização e currículo - Caminhos para assegurar o direito à aprendizagem".

${ }^{4}$ Esse significante surge no documento do MEC de 2012 - Elementos conceituais e metodológicos para definição dos direitos de aprendizagem e desenvolvimento do Ciclo de Alfabetização $\left(1^{\circ}, 2^{\circ}\right.$ e $3^{\circ}$ anos) do Ensino Fundamental - mas o escopo desse documento é restrito aos três primeiros anos do Ensino Fundamental. O documento Diálogos interdisciplinares a caminho da autoria (SÃO PAULO, 2015) amplia a "construção curricular com base em direitos de aprendizagem" (p. 5) para os outros dois ciclos do Ensino Fundamental, Ciclos Interdisciplinar e Autoral, relacionando essa perspectiva dos direitos de aprendizagem às "bases para a construção de um currículo emancipatório" que toma "os estudantes, situados historicamente, como autores de transformação social" (p. 5).
} 
sentidos, pondo em cena diferentes possibilidades de interpretação, a depender da formação discursiva em que se constitui uma determinada posição-sujeito. Se todos os alunos têm direito à aprendizagem, porque têm direito à educação, quais são os direitos (específicos em cada situação de ensino?) de aprendizagem (em contraste com à aprendizagem)?

De "direito à", locução indicativa de um processo (direito à aprendizagem, educação, alfabetização, comunicação), passa-se a "direitos de", com tônica no primeiro termo, plural, sobre o qual se produzem deslizamentos metafóricos de sentido: "direitos enquanto cidadãos", "direitos à proteção e ao desenvolvimento", mas também, "direito ao conhecimento", "direito à cidade", "direito à apropriação crítica das várias faces e dimensões da cultura humana", "direito à informação"; e, especificamente no componente curricular "Língua Inglesa" (SÃO PAULO, 2016b), "direito à diferença", "direito de aprender a língua inglesa como parte integrante de sua formação crítica" e outras formulações ${ }^{5}$ que reivindicam um "direito à língua inglesa". São enunciados que se ancoram em diferentes memórias discursivas no seu processo de significação: mais fortemente, memórias construídas na formação discursiva da cidadania e dos direitos humanos, assim como na formação discursiva da cultura, de um lado; já no componente "Língua Inglesa", o processo de significação ancora-se em memórias também construídas na formação discursiva da cidadania e dos direitos humanos, mescladas com memórias sedimentadas em torno da hegemonia da língua inglesa como língua de comunicação do mundo contemporâneo globalizado.

Mas há uma especificidade em como o enunciado "direitos de aprendizagem" funciona nesse discurso: é no espaço institucional escolar que esses direitos estão garantidos, em contraste com os enunciados "direito à educação" e "direito à aprendizagem", já garantidos na esfera constitucional. Entretanto, em seu funcionamento discursivo, esse enunciado faz parte de uma memória, instaurada pelo menos desde a promulgação da Constituição Federal de 1988, e é pela inscrição nessa memória discursiva que ele significa, ancorado no pré-construído ${ }^{6}$

\footnotetext{
${ }^{5}$ Como, por exemplo, "direito de ampliar seu [do aluno] autoconhecimento e de agir criticamente no mundo contemporâneo por meio da aprendizagem da língua inglesa" ou "direito de acessar, conhecer e refletir sobre o conjunto de patrimônios culturais produzidos e difundidos em língua inglesa".

6 Pré-construído porque tomado como um elemento que "remete a uma construção anterior" (PÊCHEUX, [1975] 1988, p. 99), já sedimentada no discurso.
} 
do "direito de todos os brasileiros à educação". Assim, no enunciado "direitos de aprendizagem", ressoa o texto da Constituição Federal de 1988, o qual faz parte de sua memória discursiva. Observa-se, portanto, o jurídico e o político afetando o funcionamento de um enunciado do âmbito educacional. Por que se deve instaurar uma determinação jurídica para fazer funcionar o que e como a escola quer ensinar?

Há, ainda, outro deslizamento de sentidos que reitera a ancoragem desse discurso na esfera legal e, portanto, sua determinação jurídica sobre a dimensão educacional e pedagógica. Trata-se da passagem, proposta no documento, de expectativas para direitos de aprendizagem, explicitada como uma mudança de perspectiva: de uma perspectiva mais técnica e instrumental para a formação e o desenvolvimento humano:

Pelas expectativas fica claro o que o aluno deve aprender, pela proposta em forma de Direitos se explicita o que o Estado e a Escola têm como dever para que o resultado geral seja eficaz. (SÃO PAULO, 2016a, p. 14)

As expectativas de aprendizagem recaem sobre o aluno, enquanto a garantia dos direitos é dever do Estado e da Escola. Mais uma vez, coloca-se o pedagógico ("o que o aluno deve aprender") sobredeterminado pelo jurídico ("o que o Estado e a Escola têm como dever"), como garantia de funcionamento do educacional, aí compreendido o pedagógico.

Retornando à distinção entre enunciado universal e enunciado histórico, em que temos o enunciado "direito à educação", formulado na Constituição Federal de 1988, como um enunciado universal, observamos, na materialidade do documento da Secretaria Municipal de Educação de São Paulo de 2016a, que o enunciado "direitos de aprendizagem" apresenta-se na forma do que Orlandi (2012b, p. 155) denomina enunciado histórico, "no sentido de que depende das configurações que sua formulação toma nas diferentes conjunturas". Na materialidade em análise, que configurações estão em jogo?

Para responder essa questão, devemos reconstruir as redes de sentido em torno desse enunciado no discurso em análise. São pelo menos três essas redes de sentido nos documentos da Secretaria Municipal de Educação de São Paulo. O enunciado "direitos de aprendizagem" é posto em relação com: 1) "Qualidade Social da Educação"; 2) "conhecimento relevante nos diversos componentes do currículo" e "construção curricular"; e 3) a formação discursiva dos Direitos Humanos. 


\title{
Examinemos estas sequências discursivas:
}

1) Qualidade Social da Educação:

\begin{abstract}
No caderno AGIR, os Direitos de Aprendizagem são relacionados à Qualidade Social da Educação. A argumentação em torno dos direitos de aprendizagem supõe uma nova organização do espaço físico das escolas, a gestão democrática, a elaboração coletiva do PPP, a formação continuada e as condições de trabalho dos profissionais. (SÃO PAULO, 2016a, p. 33, nota 14)

Os direitos de aprendizagem se consolidam pela clareza dos resultados cognitivos efetivos dos aprendizes e as condições a eles oferecidas para a realização da tarefa de aprender. De um lado, os conteúdos, os métodos, os processos didáticos, as múltiplas práticas avaliativas, as modalidades de diálogo pedagógico são claros e disponíveis e, do outro lado, o Estado e o sistema escolar devem apresentar à comunidade escolar as condições favoráveis e comprometidas para o êxito. (SÃO PAULO, 2016a, p. 14)
\end{abstract}

Nesses dizeres, a rede de sentidos refere-se à estrutura, organização e gestão do espaço escolar, em que os sujeitos desse espaço são configurados como sujeitos sociais. Os direitos de aprendizagem são dos alunos, mas a qualidade social da educação - explicitada em adequação dos recursos e processos pedagógicos e didáticos, da estrutura física, política e administrativa da escola, da formação dos profissionais - deve ser garantida pelo Estado e pelo sistema escolar. Os aprendizes são representados como sujeitos sociais que têm no Estado a garantia de execução de políticas públicas no âmbito da educação. O lugar de enunciação é o do Estado constituído em instância jurídica garantidora das políticas educacionais de Estado.

2) Conhecimento relevante nos diversos componentes do currículo e construção curricular:

\footnotetext{
Parece claro que anunciar, como direitos de aprendizagem, o que se oferece como conhecimento relevante nos diversos componentes do currículo, aponta para conceitos e temáticas amplas, que os educadores organizarão em propostas e situações que favoreçam a sua aprendizagem, dentro das condições reais das escolas e dos educandos. (SÃO PAULO, 2016a, p. 34)
}

A construção curricular com base em direitos de aprendizagem trouxe questões pertinentes também aos Ciclos Interdisciplinar e Autoral, entre elas: Quais as bases para a construção de um currículo emancipatório? Ou seja, o que não pode faltar em um documento sobre currículo para o Ensino Fundamental [...]? (SÃO PAULO, 2015, p. 5)

Os sujeitos do espaço escolar são configurados como sujeitos da educação propriamente (educadores e educandos), que, no caso específico dos educandos, 
têm direito a determinados conhecimentos considerados relevantes a um currículo emancipatório. Opera-se, assim, um recorte conceitual sobre conhecimentos e currículo, recorte esse discursivizado como direitos de aprendizagem/do aprendiz. E constrói-se a perspectiva de um currículo não primordialmente sobre o fundamento de princípios, objetivos e expectativas de aprendizagem, mas sim sobre a base de direitos de aprendizagem, fazendo ressoar o político e o jurídico à frente do filosófico-educacional e do pedagógico.

3) A formação discursiva dos Direitos Humanos:

\begin{abstract}
Defende-se formação, conhecimento, aprendizagem, considerando as/os educandas/os como sujeitos que têm direito assegurado à educação. Sujeitos de direitos e direitos de aprendizagem são questões que se articulam nesta perspectiva. (SÃO PAULO, 2016a, p. 33)

Vários estudos já foram produzidos, apontando o fundamento legal (Constituição, LDB e ECA, por exemplo) e o reconhecimento que já se atingiu sobre educadores e educandos, sobre crianças e adolescentes como sujeitos de direitos, sendo que, em todos os documentos e convenções sobre Direitos Humanos e Direitos, da Infância e da Adolescência e Direitos das Pessoas com Deficiência inclui-se a Educação como Direito. Das referências legais se destaca a relação entre direito à educação e formação e desenvolvimento humano. (SÃO PAULO, 2016a, p. 33)
\end{abstract}

É da perspectiva dos Direitos Humanos que as/os educandas/os são sujeitos de direitos e têm direito assegurado à educação, com base na legislação. Mas o discurso político-educacional, no recorte analisado, reforça esse reconhecimento e busca sua efetivação ao fazer incidir suas orientações curriculares e pedagógicas sobre essa base, por meio da articulação entre sujeitos de direitos, direitos humanos e direitos de aprendizagem, promovendo, portanto, um encontro entre o jurídico e o político. Assim, é preciso explicitar que "as/os educandas/os [são considerados] como sujeitos que têm direito assegurado à educação" e fazer referência ao "fundamento legal" desse direito, para que se faça sentido da condição de sujeitos de direitos no seio de uma sociedade na qual a cidadania e os direitos podem decair para o campo do sem-sentido ${ }^{7}$.

Conforme apontamos anteriormente, no documento da coleção Componentes curriculares relativo ao ensino da língua inglesa estabelece-se uma relação dos

\footnotetext{
${ }^{7}$ Para Orlandi (2012b, p. 167), "o sem-sentido, ao contrário [do não-sentido, que é o ainda irrealizado], resulta de um esgotamento, de processos pelos quais as coisas perdem o sentido, ou simplesmente não fazem sentido".
} 
direitos de aprendizagem com o direito à educação e a perspectiva dos direitos humanos, mas, especificamente, coloca-se o inglês - e nenhuma outra língua estrangeira - no ponto de intersecção entre o aprendiz e o mundo plurilíngue e inter/transcultural, como nesta sequência: "Direitos de Língua Inglesa: perceber-se cidadão de um mundo plurilíngue e inter/transcultural que se constitui na diferença" (SÃO PAULO, 2016b, p. 39).

O dito "direitos de língua inglesa" produz o silenciamento de outros dizeres possíveis: direitos de língua a, b, c etc., que resvalam para a dimensão do não-dito, pelo trabalho de uma política do silêncio ${ }^{8}$, conforme teorizado por Orlandi (1992). Portanto, o enunciado "direitos de língua inglesa" silencia "os direitos" de outras línguas estrangeiras igualmente passíveis de apresentarem ao aluno um "mundo plurilíngue e inter/transcultural", mas que não podem se materializar nesse espaço escolar ${ }^{9}$.

O ponto que queremos enfatizar é que enunciar todos esses aspectos do processo educacional, desde a estrutura do espaço escolar até as questões de formação e desenvolvimento humano e do direito à educação, passando pelos componentes curriculares e processos pedagógicos e didáticos, como "direitos de aprendizagem" produz um efeito de sobredeterminação: as categorias de sujeito educacional e sujeito social são sobredeterminadas pela categoria de sujeito jurídico, que é o sujeito de direito da nossa formação social capitalista. ${ }^{10}$ Quais os efeitos discursivos de se fixar com primazia a categoria de sujeito jurídico dos educandos (expressa, entretanto, na Constituição do país e em outras instâncias governamentais) em documentos que estabelecem uma política de ensino formulada por um agente de Estado? A constituição de todos os indivíduos habitantes do território brasileiro como sujeitos jurídicos já está formulada em instâncias governamentais superiores. Por que, então, dar primazia a essa categoria para

\footnotetext{
${ }^{8}$ Diz Orlandi (1992, p. 76): "se diz 'x' para não (deixar) dizer 'y', este sendo o sentido a se descartar do dito".

${ }^{9} \mathrm{~A}$ análise desse efeito de sentido será desenvolvida na seção sobre sentidos de cidadania, abaixo, com foco na designação "cidadão do mundo".

${ }^{10}$ Segundo Kashiura Jr. (2015, p. 58), "a subjetividade jurídica é, em sentido rigoroso, uma forma historicamente específica" do modo de produção capitalista. Esse sujeito jurídico, que se constitui pela interpelação ideológica, e que é, a um só tempo, "livre", porque dotado de autonomia (jurídica) e responsável pelos seus atos, e assujeitado, porque "submetido a uma estrutura social que se impõe independentemente de sua escolha” (KASHIURA JR., 2015, p. 61), é um sujeito de direito.
} 
caracterizar os educandos que serão os beneficiários da política de ensino? Por que subsumir sua condição de sujeitos educacionais à de sujeitos jurídicos?

Talvez haja um indício de resposta no próprio discurso político-educacional. $\mathrm{O}$ documento de 2015 da Secretaria Municipal de Educação de São Paulo faz a reconstituição histórica da Rede Municipal de Ensino de São Paulo, em seus aspectos políticos refletidos no currículo. Na rede de sentidos construída no texto, entrecruzam-se os direitos de aprendizagem com a determinação, pela Constituição Federal de 1988, da educação como um direito de todos e com o Estado Social e Democrático de Direito, conforme esta sequência:

A construção dos direitos de aprendizagem no Ciclo Interdisciplinar dialoga com o percurso histórico de formação social, para que se reconheça o Estado Social e Democrático de Direito como fundamental para pensar a educação. Assim, o principal divisor de águas, que marca nacionalmente o Estado Social e Democrático de Direito, é a Constituição Federal de 1988 expressão legal da superação de governos marcados pela ausência de liberdades e direitos. (SÃO PAULO, 2015, p. 9)

Marca-se, duplamente, o caráter político dos direitos de aprendizagem: são garantidos pelo Estado Social e Democrático de Direito, chancelado pela Constituição Federal de 1988, e só podem existir num estado democrático, o que faz ecoar a memória de um Estado ditatorial na história ainda recente do Brasil. Parece haver a necessidade de se garantir o direito à educação, pela via do discurso político-educacional oficial, embora assegurado na Constituição. Num país em que a condição de sujeitos de direitos não está ainda sedimentada na história como um lugar constituído, fica a tarefa de fazer funcionar os direitos nas discursividades possíveis, sendo a educação uma dessas discursividades. Cidadania, tema de nossa próxima seção, é outro lugar não constituído na história da formação do sujeito social brasileiro e que encontra na Escola uma possibilidade de realização (cf.: ORLANDI, 2001).

\section{SENTIDOS DE CIDADANIA NO DISCURSO POLÍTICO-EDUCACIONAL}

A partir dos documentos educacionais analisados, o funcionamento do enunciado "direitos de aprendizagem" subsume, por um efeito de sobredeterminação, as categorias de sujeito educacional e sujeito social à categoria de sujeito jurídico. Nas condições de produção do discurso político-educacional, a 
categoria de sujeito jurídico, por sua vez, estabelece uma relação de sentido com "cidadania", marcadamente a partir da textualidade da Constituição, que designa como um dos objetivos da educação a preparação dos sujeitos "para o exercício da cidadania" (BRASIL, 1988, Art. 205). Esse mesmo sintagma retorna na textualidade da Lei de Diretrizes e Bases da Educação Nacional (BRASIL, 1996) e, posteriormente, reformulado em diversos documentos curriculares oficiais brasileiros:

O papel fundamental da educação [...] aponta para a necessidade de se construir uma escola voltada para a formação de cidadãos. (BRASIL, 1998, p. 05, PCNs, grifos nossos)

A sociedade brasileira demanda uma educação de qualidade, que garanta as aprendizagens essenciais para a formação de cidadãos [...] (BRASIL, 1998, p. 21, PCNs, grifos nossos)

Em resumo, busca-se um ensino de qualidade capaz de formar cidadãos [...] (BRASIL, 1998, p. 45 , PCNs, grifos nossos)

[...] o direito de todo brasileiro à formação humana e cidadã e à formação profissional, na vivência e convivência em ambiente educativo. (BRASIL, 2013, p. 7, DCNs, grifos nossos) A compreensão dos estudantes como sujeitos com histórias e saberes construídos nas interações com outras pessoas, tanto do entorno social mais próximo quanto do universo da cultura midiática e digital, fortalece o potencial da escola como espaço formador e orientador para a cidadania consciente, crítica e participativa. (BRASIL, 2018, BNCC, p. 62, grifos nossos)

Segundo Pêcheux ([1975] 1988, p. 167), "a forma-sujeito [...] tende a absorveresquecer o interdiscurso no intradiscurso, isto é, ela simula o interdiscurso no intradiscurso [...]" (grifos do autor). Assim, nos dizeres selecionados, a categoria de sujeito jurídico funciona como "forma-sujeito de direito", mas é "absorvida", "esquecida" no intradiscurso pela categoria "cidadania". A forma-sujeito de direito aparece como já-dito do fio do discurso - materialidade - que restringe os sentidos de formação do sujeito a "formação cidadã do sujeito" ou "formação do sujeito como cidadão". Esse processo discursivo instaura a identificação do sujeito com a formação discursiva da "cidadania", absorvendo/esquecendo a sua relação com o interdiscurso (subjetividade jurídica, que possibilita a relação de sentido "educação como direito", como analisado na primeira parte deste artigo). Encaminhando-nos à reflexão aqui proposta, investigamos que sentidos de "cidadania" e "cidadão" (intradiscurso) articulam o sujeito com o interdiscurso, produzindo uma subjetividade jurídica específica no discurso político-educacional.

Um possível gesto de leitura desses sentidos aparece na relação de nãocoincidência que Oliveira (2006) delineia entre "cidadania" e "cidadão" em 
dicionários de português publicados no século $\mathrm{XXI}$, demonstrando que "o sentido jurídico de cidadão se liga aos direitos e deveres, seja em relação ao Estado ou a uma ética universal, e o de cidadania, aos direitos em relação ao Estado" (OLIVEIRA, 2006, p. 106). Ao analisar o discurso sobre a cidadania, Lagazzi (2010) aproxima-se desse lugar de contradições, interpretando os sentidos de cidadania como parte de uma "idealização", "um direito de conquista dos indivíduos" e, ao mesmo tempo, funcionando tautologicamente no discurso que permeia o estabelecimento de políticas públicas:

Apagada na sua constituição jurídica, a cidadania naturaliza o cidadão como um sujeito livre, consciente e lutador. [...] Apaga-se a injunção da cidadania como o modo de nos relacionarmos com o Estado, como afirma Pachukanis. O cidadão passa a ser alguém em quem depositar as esperanças de um país melhor, de uma sociedade mais promissora. Com isso, a formulação da cidadania torna-se a reafirmação constante da individualização nas sociedades de estado e passa a ser um produto democrático. (LAGAZZI, 2010, p. 82)

A pesquisadora destaca, ainda, que tais sentidos são produzidos por uma "leitura democrático-liberal", na qual a cidadania é compreendida como "ideal a ser alcançado" e o poder público, por sua vez, é tido como instrumento de garantia de "igualdade de interesses pelo bem de todos" (LAGAZZI, 2010, p. 83). É nesse gesto de interpretação que a forma-sujeito de direito, ou seja, o "sujeito jurídico", produz identificações com sentidos de "cidadão"/"cidadania", constituindo uma das principais formas sócio-ideológicas do capitalismo moderno: a forma-cidadania (ALENCAR, 2018), que, conforme analisamos, vem absorver a forma-sujeito de direito.

Também tratando da relação entre cidadania e capitalismo, Felix (2019) enfatiza que as bases dos direitos humanos (liberdade, igualdade e propriedade), elencados na Declaração dos Direitos do Homem e do Cidadão (1789) não constituem um entrave à circulação mercantil, mas, muito pelo contrário, embora escamoteados, formam os pilares que a sustentam. Desse processo de apagamento dos elementos determinantes do conceito de cidadania "decorre uma apreensão fetichizada e fetichizante da cidadania" (FELIX, 2019, p. 26), processo que o autor explica nos seguintes termos:

Como já sinalizamos, desprovida de uma análise a partir de seus fundamentos, a cidadania é, em grande parte, vista como um meio em que, a partir das lutas das classes sociais, se pode, em maior ou menor medida, construir, ampliar e consolidar direitos. Trata-se de uma forma 
parcial de apreensão de seus fundamentos, dado que se tergiversa dessa análise a relação substantiva entre a forma mercantil e a forma jurídica a ela correspondente. Relação essa que demanda a existência de sujeitos livres, proprietários e iguais, de modo a possibilitar os diferentes intercâmbios de mercadorias. (FELIX, 2019, p. 26)

Desse modo, conclui o autor que a condição genérica de "cidadão"/"sujeito de direitos" insere os sujeitos em uma mesma categoria política - "numa forma gelatinosa e fantasmagórica, que necessita anular as diferenças particulares do conjunto desses indivíduos" (FELIX, 2019, p. 29).

Trazendo essa reflexão para a análise do discurso educacional, sentidos articulados à formação discursiva da "cidadania" circunscrevem os sentidos de "formação"/"processo formativo", regulando os processos de subjetivação em jogo na instituição escolar por meio de designações como "formação cidadã do sujeito" ou "formação do sujeito como cidadão". Nesse sentido, a formação discursiva que podemos denominar "escola para formar cidadãos" mobiliza noções de "cidadania", moldando subjetividades "cidadãs", que colocam em jogo diversas contradições. Ao analisarem a relação entre cidadania e educação, Usher e Edwards (1994) trazem mais elementos para a compreensão de tais contradições, pois entendem que, na transição entre a modernidade e a pós-modernidade, a instituição escolar, enquanto Aparelho Ideológico de Estado, reconhece a diversidade, mas, ao mesmo tempo, suas relações de poder seguem em operação, oprimindo e excluindo determinados grupos sociais. Ainda segundo os autores, é nessa contradição que se inscreve a "grande narrativa da emancipação" (USHER; EDWARDS, 1994, p. 215), discurso que a pedagogia crítica vem protagonizar, transformando a educação em uma "forma de política cultural", que, conforme esclarecem os autores, reconfigura a noção de cidadania na pós-modernidade, caracterizada pela injunção aos cidadãos para se tornarem "ativos por si próprios", o que também encontra sustentação na pedagogia crítica, "para que as opressões e exclusões da modernidade não sejam reforçadas" (USHER; EDWARDS, 1994, p. 215). Os "cidadãos" são concebidos nessa lógica da "responsabilidade por si", na qual a responsabilidade do Estado torna-se cada vez menos importante e é apagada. Podemos compreender melhor tal processo de individualização se retomarmos a afirmação de Lagazzi (2010, p. 82): "a cidadania naturaliza o cidadão como um sujeito livre, consciente e lutador". A configuração dessa subjetividade vai requerer identificações com um lugar de 
possibilidade de realização dessa emancipação: a Escola. Nesse sentido, Orlandi (2001) analisa como a Escola tem se tornado um lugar de "produção de cidadãos":

Tem-se delegado à Escola a tarefa de produzir cidadãos. A Escola tem assim que "criar" a cidadania. Ela não reforça apenas algo que já estaria instalado na história social. Fica para a Escola a construção da imagem do cidadão, sendo a ciência um dos componentes dessa imagem. (ORLANDI, 2001, p. 159-160)

Ora, se à Escola cabe a "produção" de cidadãos, os sentidos de cidadania estão constituídos no lugar da falta, ou seja, é necessário que o sujeito passe por uma "transformação" para ser "cidadão". A Escola se torna esse lugar de (trans)formação do sujeito social brasileiro, fazendo retornar os sentidos de ausência/denegação de cidadania. Conforme desenvolve Orlandi (2002), ainda sobre esse tema:

[...] no Brasil, mesmo que o Estado já se tenha constituído formalmente há mais de um século, não se nasce cidadão. Não se trata assim de uma questão jurídico-política. As leis são uma projeção de um desejo. Essa tarefa - de transformação e não de direito: "virar cidadão" - fica para a educação, ou seja, é uma questão pedagógica que pode ou não atingir o sujeito social brasileiro. O que me leva a afirmar que não temos em nossa história lugar efetivo que corresponda à constituição histórica de um lugar de cidadania. (ORLANDI, 2002, p. 227-228)

A Escola constitui, na interpretação da "tópica cívica" proposta por Orlandi (2017), um lugar institucional que dá "forma e sentido aos sujeitos urbanos, aos “cidadãos'” (ORLANDI, 2017, p. 121). Discursivamente, a circulação desses sentidos encontra campo fértil no currículo enquanto "práticas discursivas que produzem e moldam saberes que, ao mesmo tempo, produzem e moldam o sujeito" (FORTES, 2016, p. 285). Somente a título de exemplo, destacamos alguns pontos do intradiscurso que marcam essa relação com o interdiscurso, ou seja, pontos de identificação com a formação discursiva "escola para formar cidadãos", a partir da textualidade do documento das Diretrizes Curriculares Nacionais (BRASIL, 2013):

Em um contexto marcado pelo desenvolvimento de formas de exclusão cada vez mais sutis e humilhantes, a cidadania aparece hoje como uma promessa de sociabilidade, em que a escola precisa ampliar parte de suas funções [...] a educação brasileira deve assumir o desafio de propor uma escola emancipadora e libertadora. (BRASIL, 2013, p. 19, DCNs, grifos nossos)

$\mathrm{Na}$ materialidade do intradiscurso, emergem sentidos de uma "educação emancipadora", que poderia concretizar a "promessa" de alcançar a "cidadania". Em outras palavras, a educação é concebida como um lugar de transformação social 
rumo à cidadania, em que a igualdade passa a ser objeto de "conquista individual", configurando o que Andreotti (2006) denominou "soft global citizenship education", uma forma de educação para a cidadania global que impõe uma visão única e individual de "mudança", sem considerar as relações de poder e as produções históricas/culturais do conhecimento. Por outro lado, Andreotti (2006) defende uma educação crítica para a cidadania global [“critical global citizenship education”], que amplia as formas de pensar e de se relacionar com os outros, não como imposição de uma "emancipação" igual para todos, mas como reconhecimento do "direito a significar" ("the right to signify"), rompendo com determinados "sistemas de crenças e práticas" (ANDREOTTI, 2006, p. 49, 50) predominantes no espaço escolar. Embora critique a perspectiva de uma "cidadania" massificada, acrítica, a pesquisadora não questiona a noção de educação como um lugar de formação para a cidadania, ressaltando a necessidade de uma abordagem "crítica" - o que mostra um ponto de identificação que retorna ao discurso de autoridade epistêmica da pedagogia crítica, predominante em diversos documentos curriculares brasileiros vigentes no sistema da Educação Básica.

Especialmente tratando dos documentos curriculares voltados ao ensino da língua inglesa, emergem outros efeitos de sentido das designações "cidadania" e "cidadão", como podemos delinear nos trechos selecionados a seguir:

\footnotetext{
A tensão entre o global e o local, ou seja, entre tornar-se pouco a pouco cidadão do mundo sem perder suas raízes, participando ativamente da vida de sua nação e de sua comunidade. (BRASIL, 1998, p. 17, PCNs)

Aprender a língua inglesa propicia a criação de novas formas de engajamento e participação dos alunos em um mundo social cada vez mais globalizado e plural, em que as fronteiras entre países e interesses pessoais, locais, regionais, nacionais e transnacionais estão cada vez mais difusas e contraditórias. Assim, o estudo da língua inglesa pode possibilitar a todos o acesso aos saberes linguísticos necessários para engajamento e participação, contribuindo para o agenciamento crítico dos estudantes e para o exercício da cidadania ativa [...] (BRASIL, 2018, p. 241, BNCC).
}

Os enunciados remetem a um sujeito "cidadão do mundo" participante de um "mundo globalizado", e se vinculam a discursos de celebração da globalização, concebida como um lugar de integração "neutra", "desideologizada", descolada de suas condições históricas e políticas (cf.: FORTES, 2016). O pré-construído que sustenta tais sentidos parece produzir-se no que Orlandi denominou o "discurso do multilinguismo" (ORLANDI, 2007, p. 59) na sociedade de mercado, em que se pratica 
o "relativismo" cultural e linguístico, aceitando-se, como é próprio à ideologia do humanismo idealista, todas as culturas e línguas, enquanto, em outro lugar, aquele que se sustenta na estrutura de poder que realmente decide, somos dominados pelo monolinguismo da língua do poder, o inglês. (ORLANDI, 2007, p. 60)

O "relativismo cultural e linguístico" do qual fala Orlandi (2007) aparece no efeito de indeterminação produzido pelas designações "cidadão do mundo" e "mundo social cada vez mais globalizado e plural". Entretanto, "não há cidadania em abstrato [...]. O que há são sítios, lugares de definição, em que se configuram processos de manifestação concreta de sentidos de cidadania" (ORLANDI, 2012a, p. 226). Na mesma direção aponta Lagazzi (2010, p. 83), quando argumenta que "[...] uma política pública consequente não pode ser uma política endereçada a todos e a qualquer um". Mas são justamente esses sentidos generalizados e generalizantes que parecem predominar no discurso político-educacional em análise, a despeito do fato de que a instituição escolar se configure como um lugar em que sentidos de cidadania específicos são produzidos, constituindo um espaço discursivo determinado pelas singularidades de línguas-culturas-sujeitos. Donde reiteramos que a designação "cidadãos do mundo" faz sentido a partir de um efeito de indeterminação vinculado ao discurso relativista do multilinguismo, que, nas condições histórico-sociais contemporâneas, encobre a determinação discursiva provocada pela hegemonia política da língua inglesa.

Tal efeito de indeterminação da designação "formação cidadã do sujeito" também aparece reiteradamente na materialidade intradiscursiva de documentos curriculares referentes ao ensino de língua inglesa no Ensino Fundamental, recentemente implementados pela Secretaria Municipal de Educação de São Paulo. A Portaria ํo 5.361 (SÃO PAULO, 2011) institui o Programa Língua Inglesa: brincar, estudar e aprender, que é justificado a partir da definição "da escola como local que deve favorecer o desenvolvimento das competências e habilidades para a inserção do cidadão no contexto globalizado" (grifos nossos). Um dos documentos curriculares que apresenta as bases do ensino desse Programa intitula-se Direitos de aprendizagem dos ciclos interdisciplinar e autoral: Língua Inglesa (SÃO PAULO, 2016b) e adota a concepção de "inglês como língua franca", contrapondo-se a outras vertentes predominantes nas pedagogias de ensino de língua inglesa no Brasil (estruturalista, instrumental etc.). Na primeira parte do documento, são 
apresentadas as diversas concepções de língua que têm pautado o ensino de inglês no Brasil e no mundo, fazendo uma genealogia de práticas e metodologias de ensino de inglês como língua estrangeira, ou seja, um levantamento históricodiscursivo conciso, mas bastante abrangente. Entretanto, na seção 2.2 do documento, temos um movimento de fechamento de sentidos: a designação "inglês como língua franca" desliza para "Inglês como Língua Franca: por uma formação crítica e cidadã" (SÃO PAULO, 2016b, p. 26). Na textualidade do documento, os sentidos de "inglês como língua franca" aparecem vinculados a "uma perspectiva crítica de ensino de línguas estrangeiras" (SÃO PAULO, 2016b, p. 26), cujo principal objetivo é a "inclusão social". É esse movimento de sentidos que podemos identificar na materialidade do fio discursivo:

O conceito de cidadania, atrelado a essa definição de crítica, também ganha novos contornos. [...] assumimos aqui a noção de "cidadania ativa" ou "cidadania engajada" em resposta à relevância da ação, do engajamento e da crítica do sujeito contemporâneo na lógica da nova política participativa [...]. (SÃO PAULO, 2016b, p. 27, grifos nossos)

No documento Currículo da cidade: Ensino Fundamental: componente curricular: Língua Inglesa (SÃO PAULO, 2019a), esse processo de metaforização também parece funcionar no movimento de sentidos ancorados no discurso da cidadania, compreendida como "senso crítico" para "garantir a inclusão do indivíduo na sociedade", reconhecendo "as capacidades críticas e criadoras [...], ao considerar e valorizar os elementos que os constituem como humanos e como cidadãos do mundo" (SÃO PAULO, 2019a, p. 20, grifos nossos). Mais adiante, no mesmo documento, reitera-se o objetivo do currículo de língua inglesa, que aparece formulado como "formar cidadãos éticos, responsáveis e solidários que fortaleçam uma sociedade mais inclusiva, democrática, próspera e sustentável" (SÃO PAULO, 2019a, p. 33, grifos nossos).

No documento Orientações didáticas do currículo da cidade: Inglês (SÃO PAULO, 2019b), a análise delineou um processo de metaforização similar na construção de sentidos sobre o ensino de língua inglesa, novamente vinculados à cidadania, à criticidade e à inclusão, com foco em uma "educação inclusiva, que pressupõe o respeito e a valorização da diversidade, a qual nos constitui como sujeitos e cidadãos de uma cidade multifacetada" (SÃO PAULO, 2019b, p. 3, grifos nossos). Outro recorte do mesmo documento reitera o papel da escola como 
promotora de "inclusão social", enfatizando que sua finalidade seria a formação de sujeitos para o "exercício de uma participação sociocultural engajada e crítica", com o propósito de "atuar como cidadãos de sua comunidade e do mundo" (SÃO PAULO, 2019b, p. 27, grifos nossos).

Ao analisar o discurso da cidadania no processo de constituição identitária de sujeitos-professores, Coracini (2007) traça o percurso de sentidos produzidos pela relação (naturalizada) cidadania-inclusão. Sua análise mostra que a cidadania é concebida "como um pacote fechado, fetichizado, onde apenas se vislumbram alguns ingredientes: criticidade, democracia, liberdade, criatividade" (CORACINI, 2007, p. 103), que, repetidos redundantemente nos documentos curriculares, tornam-se "termos esvaziados de sentido" (CORACINI, 2007, p. 101), num movimento semelhante ao campo do sem-sentido que analisamos na seção anterior.

Desse modo, compreendemos o funcionamento discursivo em análise como um processo de metaforização, que poderia ser assim formulado: língua inglesa => cidadania (global $/$ mundial) $=>$ criticidade $=>$ inclusão. Esse movimento de sentidos se constrói no discurso político-educacional por meio do percurso traçado na relação com determinadas regiões do interdiscurso, conforme vimos elaborando na análise aqui empreendida: o funcionamento da forma-sujeito de direito (sujeito jurídico), absorvida pela categoria "cidadão"; o modo peculiar do funcionamento da categoria "cidadão (crítico)" no discurso político-educacional, especialmente na formação discursiva "escola para formar cidadãos", predominante no discurso da pedagogia crítica, dentro do que Andreotti (2006) denominou "soft global citizenship education" e, nos termos de Lagazzi (2010, p. 83), "uma política endereçada a todos e a qualquer um"; e, finalmente, o processo de metaforização desses sentidos quando entram na ordem do discurso do currículo de língua inglesa, produzindo um efeito de indeterminação materializado na designação "cidadão do mundo", ancorada ao discurso relativista do multilinguismo (cf.: Orlandi, 2007), que vem escamotear a determinação discursiva da hegemonia monolíngue (inglês).

Atestando esse funcionamento discursivo na textualidade do currículo, destacase, de modo emblemático, a formulação: "O inglês está no currículo, está na escola, está na comunidade. Portanto, é direito dos estudantes se perceberem cidadãos de um mundo plurilíngue e inter/transcultural" (SÃO PAULO, 2016b, p. 32) - um processo de reconhecimento identitário que passa, necessariamente, pela 
aprendizagem da língua inglesa, e não de outra(s) língua(s), como já analisamos na primeira seção.

\section{CONSIDERAÇÕES FINAIS}

A proposta de refletir sobre o processo de produção de sentidos de direitos de aprendizagem e cidadania nos documentos oficiais nos mobilizou a um percurso de análise por meio da articulação entre discurso, língua e ensino, buscando, mais especificamente, a compreensão de algumas relações entre currículo e subjetividade. Depreendemos, a partir da análise do discurso político-educacional, que há um predomínio da forma-sujeito jurídica sobre outras subjetividades possíveis - e até mais prováveis nessa discursividade -, tais como a do sujeito educacional e a do sujeito social.

Destacaram-se, em nosso gesto de leitura da textualidade do corpus, sentidos voltados à aprendizagem como direito e à cidadania como objetivo final da formação escolar. Em outras palavras, o sujeito de direito(s), vinculado ao Estado democrático da nossa formação social capitalista, constitui a base sobre a qual o ensino e as concepções de língua se sustentam, instaurando, ao mesmo tempo, processos de identificação para os sujeitos inseridos na instituição escolar. Conforme analisamos, são os sentidos de "direitos de aprendizagem" e "cidadania" (no intradiscurso) que vêm articular o sujeito com determinadas regiões do interdiscurso (memória), produzindo uma subjetividade jurídica específica no discurso político-educacional.

Detivemo-nos em algumas equivocidades desse funcionamento discursivo, tais como "direitos de/direito a" e "cidadania/cidadão", o que nos levou à compreensão de um processo histórico e político de construção de (não) sentidos sobre esse lugar estabelecido pelo Estado para o brasileiro: um país onde a cidadania não é construída historicamente e não está garantida, embora expressa na Constituição; um país onde os direitos do cidadão de um Estado Democrático de Direito tampouco se encontram garantidos de forma plena. Essa ausência instaura um lugar da falta, fazendo com que a escola se coloque como tarefa formar cidadãos, reiterar seu compromisso com a garantia do direito à educação, pelo desdobramento desse direito em direitos plurais, e com a constituição do aluno como um sujeito de direitos. 
Assim, no discurso político-educacional que instaura as tarefas da escola, cidadania e direitos de aprendizagem se constroem como promessa de plena adequação do sujeito social brasileiro, na posição de sujeito aprendiz, ao Estado Democrático de Direito. Mas, também, no caso do ensino de inglês, a "adequação" do sujeito aprendiz ao mundo globalizado pode significar a promessa de inclusão por meio da "cidadania global" - um efeito de indeterminação sustentado pelo discurso relativista do multilinguismo (cf.: ORLANDI, 2007).

\section{REFERÊNCIAS}

ALENCAR, T. R. A face oculta da cidadania: limites, dilemas e contradições da democracia representativa. Praia Vermelha (UFRJ), Rio de Janeiro, v. 28, p. 647674, 2018.

ANDREOTTI, V. Soft versus critical global citizenship education. Policy \& Practice: A Development Education Review, [s. I.], v. 3, p. 40-51, 2006. Disponível em: http://www.developmenteducationreview.com/issue3-focus4. Acesso em: 25 ago. 2019.

BRASIL. Base Nacional Comum Curricular. Brasília: MEC/SEB, 2018.

BRASIL. Diretrizes Curriculares Nacionais Gerais da Educação Básica. Brasília: MEC; SEB; DICEI, 2013.

BRASIL. Constituição. Brasília: Planalto do Governo, 1988. Disponível em: http://www.planalto.gov.br/ccivil_03/Constituicao/Constituicao.htm. Acesso em: 19 out. 2019.

BRASIL. Elementos Conceituais e Metodológicos para Definição dos Direitos de Aprendizagem e Desenvolvimento do Ciclo de Alfabetização (1우 $2^{\circ}$ e $3^{\circ}$ anos) do Ensino Fundamental. Brasília: MEC; SEB; DICEI, 2012.

BRASIL. Lei no 9.394, de 20 de dezembro de 1996. Estabelece as diretrizes e bases da educação nacional. Brasília, DF: Presidência da República, 1996.

BRASIL. Parâmetros curriculares nacionais: terceiro e quarto ciclos do ensino fundamental: introdução aos parâmetros curriculares nacionais. Brasília: MEC/SEF, 1998.

CORACINI, M. J. R. F. Identidade e cidadania: a questão da inclusão. In: CORACINI, M. J. R. F. A celebração do outro: arquivo, memória e identidade. Campinas: Mercado de Letras, 2007. p. 97-113.

FELIX, P. R. Cidadania e capitalismo: uma análise a partir da crítica marxista do direito. Praia Vermelha (UFRJ), Rio de Janeiro, v. 29, n. 1 (Especial), p. 13-38, 2019. 
FORTES, L. Entre o silêncio e o dizível: um estudo discursivo de sentidos de bilinguismo, educação bilíngue e currículo em escolas bilíngues português-inglês. 2016. Tese (Doutorado em Letras) - Faculdade de Filosofia, Letras e Ciências Humanas, Universidade de São Paulo, São Paulo, 2016.

KASHIURA Jr., C. N. Sujeito de direito e interpelação ideológica: considerações sobre a ideologia jurídica a partir de Pachukanis e Althusser. Direito \& Práxis, Rio de Janeiro, v. 6, n. 10, p. 49-70, 2015.

LAGAZZI, S. O confronto político urbano administrado na instância jurídica. In: ORLANDI, E. P. (org.). A produção do consenso nas políticas públicas urbanas: a fabricação do consenso. Campinas: RG, 2010. p. 75-83.

OLIVEIRA, S. E. de. Cidadania: uma história da palavra. Matraga, Rio de Janeiro, v. 13, n. 19, p. 106-124, 2006.

ORLANDI, E. P. As formas do silêncio: no movimento dos sentidos. Campinas: Editora da Unicamp, 1992.

ORLANDI, E. P. Discurso e texto: formulação e circulação dos sentidos. Campinas: Pontes, 2001.

ORLANDI, E. P. Entrar na sociedade geral dos cidadãos: caminhos da história, percursos do político. In: ORLANDI, E.P. Língua e conhecimento linguístico. Para uma história das ideias no Brasil. São Paulo: Cortez, 2002. p. 215-229.

ORLANDI, E. P. Teorias da linguagem e discurso do multilinguismo na contemporaneidade. In: ORLANDI, E. P. (org.). Política linguística no Brasil. Campinas: Pontes, 2007. p. 53-62.

ORLANDI, E. P. A casa e a rua: uma relação política e social. In: ORLANDI, E. P. Discurso em análise: sujeito, sentido, ideologia. Campinas: Pontes, 2012a. p. 199234.

ORLANDI, E. P. Educação em Direitos Humanos: um discurso. In: ORLANDI, E. P. Discurso em análise: sujeito, sentido, ideologia. Campinas: Pontes, 2012b. p. 151168.

ORLANDI, E. P. Malabares - a relação entre espaços: o factual e a tópica cívica. In: ORLANDI, E. P. Eu, Tu, Ele: Discurso e real da história. 2. ed. Campinas: Pontes, 2017. p. 113-127.

PÊCHEUX, M. Semântica e discurso: uma crítica à afirmação do óbvio. Tradução de Eni Puccinelli Orlandi, Lourenço Chacon Jurado Filho, Manoel Luiz Gonçalves Corrêa, Silvana Mabel Serrani. Campinas: Editora da UNICAMP, 1988.

Originalmente publicado em 1975.

SÃO PAULO. Currículo da cidade: Ensino Fundamental: componente curricular: Língua Inglesa. 2. ed. São Paulo: SME/COPED, 2019a. 
SÃO PAULO. Diálogos interdisciplinares a caminho da autoria. Elementos conceituais e metodológicos para a construção dos direitos de aprendizagem do Ciclo Interdisciplinar. [S. I.]: Secretaria Municipal de Educação, versão de julho/2015.

SÃO PAULO. Direitos de aprendizagem dos ciclos interdisciplinar e autoral: Língua Inglesa. Coleção Componentes Curriculares em Diálogos Interdisciplinares a Caminho da Autoria. São Paulo: SME/COPED, 2016b.

SÃO PAULO. Direitos de aprendizagem nos ciclos interdisciplinar e autoral. São Paulo: SME/COPED, 2016a. (Coleção Componentes Curriculares em Diálogos Interdisciplinares a Caminho da Autoria).

SÃO PAULO. Orientações didáticas do currículo da cidade: Inglês. 2. ed. São Paulo: SME/COPED, 2019b.

SÃO PAULO. Portaria no 5.361, de 4 de novembro de 2011. Disponível em: https://www.sinpeem.com.br/lermais_materias.php?cd_materias=5867\&friurl. Acesso em: 4 out. 2019.

USHER, R.; EDWARDS, R. Postmodernism and education. London: Routledge, 1994.

\section{Sobre as autoras}

\section{Marisa Grigoletto}

Professora colaboradora sênior (aposentada) da Universidade de São Paulo, Departamento de Letras Modernas, atuando no Programa de Pós-Graduação em Estudos Linguísticos e Literários em Inglês (USP). Doutora em Linguística pela Universidade Estadual de Campinas e Livre-Docente pela Universidade de São Paulo. Líder do Grupo de Estudos e Pesquisa em Língua Estrangeira, Discurso e Identidade - LEDI (USP), registrado no Diretório de Grupos de Pesquisa do CNPq. Pesquisa nas áreas de análise do discurso pecheutiana e de linguística aplicada, com ênfase em ensino e aprendizagem de línguas, políticas de línguas, discurso colonial e constituição de identidades. Autora do livro A resistência das palavras - discurso e colonização britânica na Índia (Editora da Unicamp).

\section{Laura Fortes}

Professora da Universidade Federal da Integração Latino-Americana UNILA, atuando no Ciclo Comum de Estudos, na área de Letras e Linguística e no Programa de Pós-Graduação Interdisciplinar em Estudos Latino-Americanos (PPGIELA). Doutora em Letras (USP), com realização de estágio sanduíche na University of Technology, Sydney (UTS). Mestre em Letras (USP). Graduada e licenciada em Letras - Português/Inglês (USP). Membro do Grupo de Estudos e Pesquisa em Língua Estrangeira, Discurso e Identidade - LEDI (USP), e do Grupo de Pesquisa Linguagem, Política e Cidadania, (UNILA). Tem experiência no ensino de inglês e português como línguas estrangeiras. Dedica-se aos estudos da análise de discurso pecheutiana, em relação de entremeio com a linguística aplicada e com a história das ideias linguísticas, com foco nos seguintes temas: ensino e aprendizagem de línguas, bi/multilinguismo, currículo, políticas de línguas e formação docente. 